\title{
Correction to: Quantitative topographic anatomy of the femoral ACL footprint: a micro-CT analysis
}

Danielle G. Norman ${ }^{1}$ - Alan Getgood ${ }^{2} \cdot$ John Thornby $^{1}$. Jonathan Bird ${ }^{3}$ - Glen A. Turley ${ }^{1}$. Tim Spalding ${ }^{4}$. Mark A. Williams ${ }^{1}$

Published online: 13 November 2017

(C) International Federation for Medical and Biological Engineering 2017

Correction to: Med Biol Eng Comput (2014) 52:985-995

https://doi.org/10.1007/s11517-014-1196-0

An author has corrected their first name and updated their email address - see the affiliation section below. Daniel G. Norman should now be Danielle G. Norman as shown in the authorgroup section above.

The online version of the original article can be found at https://doi.org/ 10.1007/s11517-014-1196-0

Danielle G. Norman

d.norman.3@warwick.ac.uk

1 WMG, The University of Warwick, Coventry CV4 7AL, UK

2 Fowler Kennedy Sport Medicine Clinic, University of Western, London, Ontario, Canada

3 Department of Trauma and Orthopaedics, University Hospital Lewisham, London, UK

4 University Hospitals Coventry and Warwickshire, Coventry, UK 